\title{
Demographic Determinants of Health Care-Seeking Behaviour among Women in Khana Local Government Area of Rivers State, Nigeria
}

\author{
Nwiko, Kuebeari M. ${ }^{1}$, Asogwa, Emmanuel U. ${ }^{2}$, Achalu, Ernest I. ${ }^{3}$ \\ ${ }^{1,2,3}$ Department of Human Kinetics and Health Education, University of Port Harcourt, Nigeria. \\ Corresponding Author: Nwiko, Kuebeari M.
}

DOI: https://doi.org/10.52403/ijrr.20220137

\begin{abstract}
The study investigated the demographic determinants of health care-seeking behaviour among women in Khana Local Government Area of Rivers State. Five research questions and one hypothesis guided the study. Descriptive cross-sectional design was adopted. The sample size of 1,200 women was selected using multi-stage sampling procedures. Selfstructured instrument, whose reliability was determined using Cronbach Alpha Correlation was used for data collection. The study utilized statistical tools of Mean Standard deviation and one-way Analysis of Variance (ANOVA) to analyze the data. The result of the study showed that the respondents had good health careseeking behaviour in terms of action on perceived signs and symptoms $(\bar{x}=2.67 \pm$ 0.89 ), test-seeking ( $\bar{x}=2.93 \pm 0.94)$, choice of health care services $(\bar{x}=3.36 \pm 0.76)$, treatmentseeking $(\bar{x}=2.86 \pm 0.95)$, and treatmentadherence $(\bar{x}=2.87 \pm 0.85)$. The findings also showed that demographic factors of age ( $\mathrm{F}=8.767, \mathrm{P}<0.000)$, occupation $(\mathrm{F}=19.304, \mathrm{P}$ $<0.000)$, educational level $(\mathrm{F}=3.019, \mathrm{P}<$ $0.029)$, and income level $(\mathrm{F}=4.680, \mathrm{P}<0.003)$ were significant determinants of health care seeking behaviour of the women. The study recommended among others that women should be empowered more through educational and employment opportunities
\end{abstract}

Keywords: Demographic Factors, and Health Care-Seeking Behaviour

\section{INTRODUCTION}

Individuals encounter one health problem or the others at one's life time, and to seek solutions to health problems, individuals seek healthcare or treatment for cure and improvement. Olenja (2003) defines healthcare-seeking behaviour as any action or inaction undertaken by individuals who perceive they have a health problem or illness for the purpose of finding on appropriate remedy. According to studies, people seek healthcare for a number of reasons such as to receive treatment for acute or ongoing or chronic medical conditions for disease prevention, and health promotion purposes, or to satisfy some social or personal needs such as family planning, or employment purpose (Sauver, Warriner, Yawa, Jacobson, McGree, Pankratz \& Rocca, 2013).

Healthcare-seeking behaviour has five components which include action on perceived signs and symptoms, test seeking behaviour, choice of health care behaviour, treatment-seeking behaviour and treatmentadherent behaviour (Obiechina, 2014). Literature reveals that health care-seeking behaviour depends on the action undertaken by individuals in response to signs and symptoms. Hjelm and Atwine (2011) stated that health care-seeking behaviour is influenced by manifestation of symptoms. While some may perceive signs and symptoms as something that needs urgent attention, others may perceive symptoms of 
disease as too trivial to take off their busy schedule to seek treatment. Test-seeking behaviour could facilitate early detection thereby leading to either prevention or treatment, and quick recovery. Test seeking behaviour delay may either result in patients' failure to seek health care or inability of health system to detect disease on time. According to Obiechina (2014), delay in test-seeking may result in more severe illness consequences. Mirandola, et al 92017) describe test-seeking as the active search by individuals to be tested in order to know their health status.

Studies identify a lot of factors that could influence people's choice of treatment. These factors include genetic, life events or temperament (Nwiko, 2021) enabling factors, such as availability and accessibility of resources or services (Nnorom, 2019). Treatment-seeking behaviour, according to researchers also depends on various factors such as availability of drugs, access to treatment, symptoms of relief or lack of relief, complexity of treatment guidelines, and dissatisfaction with the health care providers or the services (Obiechina, 2014). Morankar and Admassu (2013) state that treatmentseeking behaviour of men and women is largely dependent on how he/she and those around him or her perceive the causes, regard the diagnosis, accept the treatment, and adhere to treatment.

Treatment-adherence or medication adherence is the extent to which patients or health care consumers take medication as prescribed by their health care providers (Osterberg \& Blaschke, 2005). Treatmentadherence behaviour implies that a patient follows strictly recommended course of treatment, taking all the prescribed medications for the entire length of the regimen (Nwako, 2021).

Generally, health care-seeking behaviour of person or persons is influenced or determined by a number of factors, ranging from personal, demographic, healthcare providers' and quality of health care factors. Oberoi, Chaudhary, Patnaik and Singh (2016) identified determinants of health care-seeking behaviour to include a variety of socio-cultural economic and environmental factors, influenced by intrapersonal and interpersonal characteristics and behaviours, community norms and expectations together with available provider services.

Demographic factors such as age, occupation, educational level and income levels have strongly been linked with health care-seeking behaviour according to studies. Baker et al (2011) opined that socioeconomic status which comprises individuals' social and economic standing reflecting their educational levels, income and occupation had been significantly associated with health care-seeking behaviour. A research work of Baker et al (2011) also showed that high level of education improves health knowledge, literacy, beliefs, and practice, and is associated with good health and positive health outcomes. Mohammadbeigi et al (2018) reported a direct relationship between education attainment and actual use of health care.

Health care of any form comes at a cost and individual income may directly influence healthcare-seeking behaviour. Adam and Aigbokhaode (2018) reported that income is an important determinant of health care seeking behaviour and health insurance status. It is most likely that persons with good income can afford costs for health test screening and treatment more than persons in very low income level. However, researchers reported conflicting findings on the effect of age on healthcare seeking behaviour. Adam and Aigbokhaide (2018) reported that health care-seeking behaviour increases with increasing in age. Thompson, et al (2016) concur that older people, especially people with chronic health problems are more likely to seek regular or multiple sources of care. Contrarily, study reports of Ahmed, Jomson, Petzold and Kabir (2005) revealed no significant differences in healthcare-seeking patterns between the elderly and the young, 
but reinforced that socio-economic factors such as income and educational status are more important predictors of healthcareseeking behaviour than age and gender.

It is discovered that available health care facilities and services in developing countries are not often utilized to protect, maintain and promote, and even restore health. And this low and non-utilization of available health care services has been largely due to health care consumers' or patients' health-seeking behaviour influenced by a number of factors, hence, the need to investigate demographic factors that determine health care-seeking behaviour among women in Khana Local Government Area of Rivers State.

\section{Research Questions}

1. What is the healthcare-seeking behaviour among women in Khana Local Government Area of Rivers State?

2. What is the extent to which age determine healthcare-seeking behaviour among women in Khana Local Government Area of Rivers State?

3. To what extent does occupation determine healthcare-seeking behaviour among women in Khana Local Government Area of Rivers State?

4. What is the extent to which educational level determine healthcare-seeking behaviour among women in Khana Local Government Area of Rivers State?

5. To what extent does income determine healthcare-seeking behaviour among women in Khana Local Government Area of Rivers State?

\section{Hypothesis}

Demographic factors of age, occupation, educational level and income are not significant determinants of healthcare-seeking behaviour among women in Khana Local Government Area of Rivers State.

\section{METHODOLOGY}

The study adopted descriptive crosssectional survey design. A sample size of 1,200 women was selected using multi-stage procedures. A 49-item self-structured questionnaire titled Healthcare-Seeking Behaviour Questionnaire (HCSBQ) which was designed in line with modified Likert type Scale of Always, Sometimes, Rarely and Never was used for data collection. The reliability of the instrument was tested using test re-test method with reliability coefficient ${ }^{\circledR}$ value of 0.64 . Mean and Standard Deviation were used to answer the research questions, while one-way Analysis of Variance (ANOVA) was used to test the hypothesis at 0.05 alpha level.

\section{RESULTS}

Research Question 1: What is the healthcare-seeking behaviour among women of Khana Local Government Area of Rivers State?

Table 1: Healthcare-seeking behaviour among women of Khana Local Government Area of Rivers State $(\mathrm{N}=1200)$

\begin{tabular}{|l|l|c|c|c|}
\hline S/N & Healthcare-seeking behaviour & $\bar{x}$ & SD & Remark \\
\hline 1 & Healthcare-seeking behaviour on signs and symptoms & 2.67 & .89 & Positive \\
\hline 2 & Test-seeking behaviour & 2.93 & .94 & Positive \\
\hline 3 & Choice of healthcare behaviour & 3.36 & .76 & Positive \\
\hline 4 & Treatment-seeking behaviour & 2.86 & .95 & Positive \\
\hline 5 & Treatment-adherent behaviour & 2.87 & .85 & Positive \\
\hline & Overall grand Mean & 2.94 & .88 & Positive \\
\hline
\end{tabular}

Data on table 1 showed that the respondents exhibited good, choice of health care behaviour $(\bar{x}=3.36 \pm 0.76)$, followed by test-seeking behaviour $(\bar{x}=2.93 \pm 0.44)$, treatment-adherent behaviour $(\bar{x}=2.87 \pm$ $0.85)$, treatment-seeking behaviour $(\bar{x}=2.86$ $\pm 0.95)$, treatment seeking behaviour $(\bar{x}=$
$2.86 \pm 0.95)$, and health care seeking behaviour on signs and symptoms $(\bar{x}=2.67$ \pm 0.89),. The table further showed the overall grand mean score of 2.94 which is greater than the criterion mean of 2.50, indicating that women of Khana Local 
Government Area of Rivers State had good health care-seeking behaviour.
Research Question 2: What is the extent to which age determine health care-seeking behaviour among women of Khana Local Government Area of Rivers State?

Table 2: Extent Age Determine Healthcare-seeking Behaviour ( $N=1200)$

\begin{tabular}{|c|c|c|c|c|c|c|c|c|c|c|c|c|c|}
\hline & \multicolumn{2}{|l|}{ Healthcare-seeking behaviour } & \multicolumn{4}{|c|}{$\begin{array}{l}\text { 16-25yrs } \\
(\mathrm{n}-291)\end{array}$} & \multicolumn{2}{|c|}{$\begin{array}{l}26-35 y r s \\
(n-386)\end{array}$} & \multicolumn{3}{|c|}{$\begin{array}{l}36-45 y r s \\
(n=254)\end{array}$} & \multicolumn{2}{|c|}{$\begin{array}{l}54 \text { \& above } \\
(n=269)\end{array}$} \\
\hline & & $\bar{x}$ & SD & RMK & $\bar{x}$ & SD & SD & $\bar{x}$ & SD & RMK & $\bar{x}$ & SD & RMK \\
\hline 1 & Behaviour on signs and symptoms & 2.68 & .46 & $\mathrm{P}$ & 2.78 & .51 & $\mathrm{P}$ & 2.60 & .41 & $\mathrm{P}$ & 2.56 & .41 & $\mathrm{P}$ \\
\hline 2 & Test-seeking behaviour & 2.91 & .50 & $\mathrm{P}$ & 3.01 & .48 & $\mathrm{P}$ & 2.84 & .47 & $\mathrm{P}$ & 2.94 & .34 & $\mathrm{P}$ \\
\hline 3 & Choice of healthcare behaviour & 3.55 & .45 & $\mathrm{P}$ & 3.59 & .40 & $\mathrm{P}$ & 3.51 & .55 & $\mathrm{P}$ & 3.58 & .41 & $\mathrm{P}$ \\
\hline 4 & Treatment-seeking behaviour & 2.89 & .32 & $\mathrm{P}$ & 2.82 & .38 & $\mathrm{P}$ & 2.74 & .42 & $\mathrm{P}$ & 2.82 & .18 & $\mathrm{P}$ \\
\hline 5 & Treatment Adherent behaviour & 2.86 & .46 & $\mathrm{P}$ & 2.86 & .52 & $\mathrm{P}$ & 3.16 & .60 & $\mathrm{P}$ & 2.32 & .49 & $\mathrm{P}$ \\
\hline & Overall Grand mean & 2.97 & .43 & $\mathrm{P}$ & 3.00 & .45 & $\mathrm{P}$ & 2.97 & .49 & & 2.90 & .36 & \\
\hline & & & & \multicolumn{10}{|c|}{$\begin{array}{l}\text { RMK = Remark } \\
\mathrm{P}=\text { Positive }\end{array}$} \\
\hline
\end{tabular}

Table 2 showed that the respondents of all age groups demonstrated positive healthcare-seeking behaviour. The results also showed that the overall grand mean scores in all the components of healthcareseeking behaviour of 3.00 for 26-35 years, 2.97 for 16-25 years, 2.97 for 36-45 years and 2.90 for 46 years and above, confirmed that age had positive influence on healthcare seeking behaviour among women of Khana Local Government Area of Rivers State.

Research Question 3: To what extent does occupation determine healthcare-seeking behaviour among women in Khana Local Government Area of Rivers State?

Table 3: Extent occupation determine healthcare-seeking behaviour $(\mathrm{N}=1200)$

\begin{tabular}{|c|c|c|c|c|c|c|c|c|c|c|c|c|c|}
\hline & \multicolumn{2}{|l|}{ Healthcare-seeking behaviour } & \multicolumn{4}{|c|}{$\begin{array}{l}\text { Farmers } \\
(\mathbf{n}-207)\end{array}$} & \multicolumn{2}{|c|}{$\begin{array}{l}\text { Traders } \\
(n-437)\end{array}$} & \multicolumn{3}{|c|}{$\begin{array}{l}\text { Civil Servant } \\
(\mathbf{n}=377)\end{array}$} & \multicolumn{2}{|c|}{$\begin{array}{l}\text { Public } \\
(n=179)\end{array}$} \\
\hline & & $\bar{x}$ & SD & RMK & $\bar{x}$ & SD & RMK & $\bar{x}$ & SD & RMK & $\bar{x}$ & SD & RMK \\
\hline 1 & $\begin{array}{l}\text { Behaviour on signs and } \\
\text { symptoms }\end{array}$ & 2.55 & .35 & $\mathrm{P}$ & 2.77 & & $\mathrm{P}$ & 2.64 & .52 & $\mathrm{P}$ & 2.67 & .41 & $\mathrm{P}$ \\
\hline 2 & Test-seeking behaviour & 2.97 & .47 & $\mathrm{P}$ & 2.48 & .46 & $\mathrm{P}$ & 2.92 & .45 & $\mathrm{P}$ & 2.80 & .45 & $\mathrm{P}$ \\
\hline 3 & $\begin{array}{l}\begin{array}{l}\text { Choice of } \\
\text { behaviour }\end{array} \\
\end{array}$ & 3.52 & .43 & $\mathrm{P}$ & 3.58 & .45 & $\mathrm{P}$ & 3.62 & .29 & $P$ & 3.39 & .63 & $\mathrm{P}$ \\
\hline 4 & Treatment-seeking behaviour & 2.82 & .36 & $\mathrm{P}$ & 2.81 & .47 & $\mathrm{P}$ & 2.82 & .29 & $\mathrm{P}$ & 2.79 & .31 & $\mathrm{P}$ \\
\hline 5 & Treatment Adherent behaviour & 2.94 & .57 & $\mathrm{P}$ & 3.01 & .39 & $\mathrm{P}$ & 2.73 & .51 & $\mathrm{P}$ & 2.73 & .61 & $\mathrm{P}$ \\
\hline & Overall Grand mean & 2.96 & .43 & $\mathrm{P}$ & 3.03 & .50 & $\mathrm{P}$ & 2.94 & .41 & & 2.86 & .48 & \\
\hline
\end{tabular}

The data on the Table 3 showed overall grand mean scores, which indicated that those respondents who were traders exhibited better health care seeking behaviour $(\bar{x}=3.03 \pm 0.45)$, followed by farmers $(\bar{x}=2.96 \pm 0.43)$, and civil servants $(\bar{x}=2.94 \pm 0.41)$, and public servants $(\bar{x}=$ $2.86 \pm 0.48)$. All the overall grand mean scores are greater than the criterion mean of 2.50, showing that occupation greatly determined the healthcare-seeking behaviour of the respondents.

Research Question 4: What is the extent to which educational level determine health care-seeking behaviour among women of
Khana Local Government Area of Rivers State?

The overall grand mean scores in Table 4 showed that respondents with a secondary school education exhibited more positive healthcare-seeking behaviour than others with $(\bar{x}=2.98 \pm 0.45)$, followed by those with primary education $(\bar{x}=2.97 \pm$ $0.47)$, tertiary education $(\bar{x}=2.95 \pm 0.43)$, and those who had no formal education $(\bar{x}$ $=2.89 \pm 0.42)$. The finding also showed that respondents in other levels of education exhibited better healthcare-seeking behaviour than the those with no formal education, indicating that educational level 
Nwiko, Kuebeari M. et.al. Demographic determinants of health care-seeking behaviour among women in khana local government area of Rivers State, Nigeria.

to some extent determined healthcare- seeking behaviour of the women.

Table 4: Extent to which educational level determine healthcare-seeking behaviour $(\mathrm{N}=1200)$

\begin{tabular}{|c|c|c|c|c|c|c|c|c|c|c|c|c|c|}
\hline & \multicolumn{2}{|l|}{ Healthcare-seeking behaviour } & \multicolumn{4}{|c|}{$\begin{array}{l}\text { None } \\
(\mathrm{n}-71)\end{array}$} & \multicolumn{2}{|c|}{$\begin{array}{l}\begin{array}{l}\text { Primary } \\
\text { (n-147) }\end{array} \\
\end{array}$} & \multicolumn{3}{|c|}{$\begin{array}{l}\text { Secondary } \\
(n=154)\end{array}$} & \multicolumn{2}{|c|}{ Tertiary $(n=468)$} \\
\hline & & $\bar{x}$ & SD & RMK & $\bar{x}$ & SD & RMK & $\bar{x}$ & SD & RMK & $\bar{x}$ & SD & RMK \\
\hline 1 & Behaviour on signs and symptoms & 2.46 & .34 & $\mathrm{P}$ & 2.66 & .33 & $\mathrm{P}$ & 2.71 & .44 & $\mathrm{P}$ & 2.66 & .53 & $\mathrm{P}$ \\
\hline 2 & Test-seeking behaviour & 2.81 & .54 & $\mathrm{P}$ & 2.91 & .47 & $\mathrm{P}$ & 2.96 & .47 & $\mathrm{P}$ & 2.93 & .42 & $\mathrm{P}$ \\
\hline 3 & Choice of healthcare behaviour & 3.53 & .34 & $\mathrm{P}$ & 3.45 & .70 & $\mathrm{P}$ & 3.55 & .45 & $\mathrm{P}$ & 3.59 & .36 & $\mathrm{P}$ \\
\hline 4 & Treatment-seeking behaviour & 2.74 & .28 & $\mathrm{P}$ & 2.90 & .39 & $\mathrm{P}$ & 2.79 & .37 & $\mathrm{P}$ & 2.82 & .30 & $\mathrm{P}$ \\
\hline 5 & Treatment Adherent behaviour & 2.95 & .42 & $\mathrm{P}$ & 2.95 & .49 & $\mathrm{P}$ & 2.92 & .53 & $\mathrm{P}$ & 2.77 & .59 & $\mathrm{P}$ \\
\hline & Overall Grand mean & 2.89 & .42 & & 2.97 & .47 & & 2.98 & .45 & & 2.95 & .43 & \\
\hline
\end{tabular}

Research Question 5: To what extent does income determine healthcare-seeking behaviour among women of Khana Local Government Area of Rivers State?

Table 5: Extent to which income determine healthcare-seeking behaviour $(N=1200)$

\begin{tabular}{|c|c|c|c|c|c|c|c|c|c|c|c|c|c|}
\hline & \multicolumn{2}{|l|}{ Healthcare-seeking behaviour } & \multicolumn{4}{|c|}{$\begin{array}{l}\text { None } \\
(n-71)\end{array}$} & \multicolumn{2}{|c|}{$\begin{array}{l}\text { Primary } \\
(n-147)\end{array}$} & \multicolumn{3}{|c|}{$\begin{array}{l}\text { Secondary } \\
(\mathrm{n}=154)\end{array}$} & \multicolumn{2}{|c|}{ Tertiary $(n=468)$} \\
\hline & & $\bar{x}$ & SD & RMK & $\bar{x}$ & SD & RMK & $\bar{x}$ & SD & RMK & $\bar{x}$ & SD & RMK \\
\hline 1 & Behaviour on signs and symptoms & 2.63 & .44 & $\mathrm{P}$ & 2.73 & .44 & $\mathrm{P}$ & 2.80 & .60 & $\mathrm{P}$ & 2.69 & .88 & $\mathrm{P}$ \\
\hline 2 & Test-seeking behaviour & 2.91 & .46 & $\mathrm{P}$ & 3.01 & .38 & $\mathrm{P}$ & .296 & .54 & $\mathrm{P}$ & 2.86 & .53 & $\mathrm{P}$ \\
\hline 3 & Choice of healthcare behaviour & 3.58 & .41 & $\mathrm{P}$ & 3.48 & .58 & $\mathrm{P}$ & 3.58 & .39 & $\mathrm{P}$ & 3.46 & .35 & $\mathrm{P}$ \\
\hline 4 & Treatment-seeking behaviour & 2.79 & .35 & $\mathrm{P}$ & 2.83 & .33 & $\mathrm{P}$ & 2.75 & .27 & $\mathrm{P}$ & 3.05 & .35 & $\mathrm{P}$ \\
\hline 5 & Treatment Adherent behaviour & 2.84 & .56 & $\mathrm{P}$ & 2.84 & .47 & $\mathrm{P}$ & 3.02 & .60 & $\mathrm{P}$ & 3.17 & .49 & $\mathrm{P}$ \\
\hline & Overall Grand mean & 2.95 & .44 & $\mathrm{P}$ & 2.97 & .44 & & 3.02 & .48 & & 3.04 & .43 & \\
\hline & & & & \multicolumn{10}{|c|}{ RMK $=$ Remark, $\mathrm{P}=$ Positive } \\
\hline
\end{tabular}

The overall grand mean scores presented in Table 5 showed that respondents who had high income of N70,000 and above exhibited more positive healthcare-seeking behaviour than others with $(\bar{x}=3.04 \pm 0.43)$, followed by those with N51-N70,000 ( $\bar{x}=3.02 \pm 0.48)$, N30$\mathrm{N} 50,000(\bar{x}=2.97 \pm 0.44)$, and less than $\mathrm{N} 30,000((\bar{x}=2.95 \pm 0.44)$. The implication of the finding on the table is that high income was very important determinant of healthcare-seeking behaviour among women of Khana Local Government Area.

\section{Test of Hypothesis}

Demographic factors of age, occupation, educational level and income level are not significant determinants of healthcare-seeking behaviour among women of Khana Local Government Area of Rivers State

Table 6: One-way Analysis of Variance (ANOVA) showing extent to which demographic factors determine healthcare-seeking behaviour

\begin{tabular}{|l|l|l|l|l|l|l|}
\hline Sources of variance & Sum of squares & Df & Mean sum of signs & F-value & R-value & Decision \\
\hline Age & & & & & & \\
\hline Between group & 1.475 & 3 & .492 & 8.767 & .000 & Rejected \\
\hline Within group & 56.492 & 1007 & .056 & & & \\
\hline Total & 57.969 & 1010 & & & & \\
\hline Occupation & & & & & & \\
\hline Between group & 3.152 & 3 & 1.057 & 19.304 & .000 & Rejected \\
\hline Within group & 54.817 & 1007 & .054 & & & \\
\hline Total & 57.969 & 101 & & & & \\
\hline Educational & & & & & & \\
\hline Between group & .517 & 3 & .772 & 3.019 & .029 & Rejected \\
\hline Within group & 57.452 & 1007 & .057 & & & \\
\hline Total & 57.969 & 1010 & & & & \\
\hline Income level & & & & & & \\
\hline Between group & .797 & 3 & .266 & 4.680 & .003 & Rejected \\
\hline Within group & 57.72 & 1007 & .057 & & & \\
\hline Total & 57.969 & 1010 & & & & \\
\hline
\end{tabular}


Table 6 showed that age $[\mathrm{F}(3,1007)$ $=8.767, \mathrm{P}<0.05]$, occupation $[\mathrm{F}(3,1007)=$ 19.304, $\mathrm{P}<0.05]$, Education, $[\mathrm{F}(3,1007)=$ 3.019, $\mathrm{P}<0,05]$, and income level $[\mathrm{F}$ $(3,1007)=4.680, \mathrm{P}<0.05]$ significantly determined healthcare-seeking behaviour among women in Khana Local Government Area of Rivers State, hence the hypothesis which states that demographic factors are not significant determinants of healthcareseeking behaviour among women of Khana Local Government Area of Rivers State was rejected.

\section{DISCUSSION OF FINDINGS \\ Healthcare-seeking Behaviour}

The study's findings in Table 1 revealed that the women of Khana Local Government Area had good healthcare seeking behaviour in terms of action on signs and symptoms, test-seeking, choice of healthcare, treatment-seeking and treatment adherent. This finding on the action on signs and symptoms corroborates the study reports of Mahejabin, Paveen and Begum (2015) that revealed that $80.4 \%$ of their respondents sought healthcare services during notice of signs and symptoms (ie sickness or illness). This finding of the study is also consistent with Danso-Appiah et al, (2010) discovery which revealed that one of the most important determinants of seeking health care or inviting a health facility is perceived severity of symptoms.

The encouraging test-seeking behaviour among women in Khana Local Government Area is in line with the findings of Ren et al (2019) who reported that 2,383 men who had sex with men in China engaged in HIV self testing, but in contrary, Obiechina's study (2014), found out that majority of tuberculosis patients in Ibadan, Oyo, States did not carry out test to confirm their TB status. The good test seeking behaviour of the respondents of this study could be attributed to their access to health information on many social media platforms, advising people on regular medical check ups. More so, there are presently many diagnostic facilities located in different communities, and also availability of self-diagnostic devices.

The findings of the study also showed that respondents demonstrated good healthcare-seeking behaviour in terms of choice of healthcare services. They chose treatment centers available in their community and nearest to their house, affordable, and effective, where best treatment and attention is given. This encouraging healthcare-seeking behaviour of these women must be as a result of improved primary healthcare delivery in Nigeria, especially in Rivers State, where many top international oil exploration companies partner with state governments in Niger-Delta region to construct modern comprehensive health centres in communities. However, this finding is not in agreement with Obiechina (2014) who observed poor choice of healthcare services among TB patients and attributed the poor response on choice of health care services to factors such as family decision on where a patient goes for treatment, use of home remedies, traditional healing, preference to private choices and spiritual healing.

The finding that women of Khana LGA had good treatment-seeking behaviour agrees with findings of Khajeh et al (2019) which showed that nearly eighty percent of their participants took to self-medication, and most of them preferred public hospital as their first point of contact with health system, and others visited family physicians. The finding of this study also corroborated Harod (2016) work on students' healthcare seeking behaviour which reported that in response to imagined abdominal pain, $31.1 \%$ of the students rested and awaited for self-resolution, $22.7 \%$ took to over-the-counter medication, $18.2 \%$ consulted healthcare professionals, and $11.4 \%$ took home remedy. These findings implied that the respondents demonstrated treatment-seeking behaviour, irrespective of the avenues/sources of care.

On treatment-adherent behaviour, the finding revealed that the respondents exhibited good treatment-adherent 
behaviour in terms of making out time to go for treatment, taking mediations as prescribed. However, good number of the respondents had bad treatment-adherent behaviour in terms of not being able to keep every clinic appointment due to work tight schedule, and forgetting to take their medication as prescribed. The finding is, however, in contrast with the findings of Dida et al (2015) who reported $66.2 \%$ of non-adherence rate among patients with epilepsy in Brasil, due to increased treatment complexities, age and gender, and also study reports of Baudeth (2013) which indicated negative treatment adherence behaviour among patients receiving antiretroviral therapy in Namibia, attributing it to factors, such as spiritual belief, cultural beliefs, stigma, discrimination, nondisclosure of HIV status, and unwillingness to take medication in the presence of others.

\section{Demographic Factors as Determinants of Healthcare-seeking Behaviour}

The results in Table 2 showed that respondents of all the age groups: 16-25 years, 26-35 years, 36-45 years and 46 years and above exhibited good healthcareseeking behaviour, indicating that age significantly determined the healthcare seeking behaviour of women of Khana local government Area. This finding corroborated Adam and Aigbokhaoade (2018) finding that healthcare-seeking behaviour increases with increasing age. Mohammed (2014) also concur that age has a significant effect on healthcare-seeking behaviour among the aged.

Table 3 showed the result, which presented that occupation had significant positive impact on healthcare-seeking behaviour among women of Khana Local Government Area of Rivers State. This finding agrees with Obiechina (2014) who found that farmers, businessmen and women, civil servants and those with no job sought care on notice of signs and symptoms of disease. The findings are however, in contrast with Yimer et al (2009) who noted that people with full-time job are usually too busy to seek professional health care especially when they perceive the symptoms as not be severe enough to justify stopping their work seeking treatment.

Result in Table 4 showed that respondents of different educational levels displayed good health care-seeking behaviour. The finding revealed that education was a strong determinant in healthcare -seeking behaviour. This finding is consistent with the Gosh et al (2013) report that literate or educated mothers were found to seek health care more $(78.3 \%)$ than illiterate mothers. They concluded that literacy status of mothers besides other factors was found to be positively associated with healthcare seeking behaviour.

Table 5 presented result which showed that all the respondents with source of income or in one level of income to another exhibited good healthcare seeking behaviour, showing that income significantly impacted on the good healthcare seeking behaviour of Khana positively and proved to be a important determinant of healthcare-seeking behaviour. This finding is in agreement with the work of Latunyi and Akinyemi (2018) which revealed that the respondents that were employed or who were income earners sought healthcare based on their financial capacities; some in private sectors and some in public health facilities. They further noted that education and income increase accessibility to all forms of healthcare, thereby increasing level of good healthcare seeking behaviour of patients and healthcare consumers.

\section{CONCLUSION}

The study concluded based on the findings that women in Khana Local Government Area of Rivers State had good healthcare seeking behaviour in terms of action on signs and symptoms, test-seeking, choice of healthcare services, treatmentseeking and treatment-adherent. And that demographic factors age, occupation, educational level and income were significant determinants on healthcare- 
seeking behaviour among women in Khana Local Government Area.

\section{Recommendations}

1. Government at all levels and voluntary agencies should empower women more through education and employment opportunities so as to sustain and improve on their healthcare-seeking behaviour and practices.

2. Stakeholders and healthcare service providers should address adequately quality service-related factors, such as good service delivery, proximity, affordability, prompt healthcare attention, and ready availability of drugs, to ensure proper healthcare seeking behaviour of all healthcare consumers and patients both in urban and rural areas.

3. There should be health education programmes both in and outside schools to educate students and public on the appropriate healthcare seeking actions and behaviours, and enlighten them on the negative impact of harmful health practices and lifestyles, and nonutilization of available healthcare services and facilities.

\section{Acknowledgement: None}

\section{Conflict of Interest: None}

\section{Source of Funding: None}

\section{Ethical Approval: Approved}

\section{REFERENCES}

1. Adam, V. Y. \& Aigbokhaode, A. O. (2018). Socio-demographic factors associated with the healthcare-seeking behaviour of heads of households in a rural community in a southern Nigeria, Shahel medical Journal $121 ; 31-36$.

2. Ahmed, S. M., Adams, A. M., Chousdhury, M., \& Bhuiya, A. (2000). Gender, Socioeconomic development and healthseeking behaviour on Bangladesh, Social Science and Medicine, 57 (3), 361-371.
3. Baker, D. P., Leon, T., Smith-Greenway, E G., Collins, T. \% Movit, M. (2011). The education effect on population health: A reassessment Population and Development review 37 (2), 307-332.

4. Balath, M. F. (2013). Factors associated with poor adherence amongst patients receiving antiretroviral therapy at the intermediate hospital, Oshoakati in Nambia. A Master's Dissertation, University of Western Cape.

5. Danso, Appiah, A., Stolk, W, A., Bosompen, K. M., Otchere, J., Looman, C, W. N., Habbema, J. D. F., \& deVlas, S. T. (2010). Health seeking behaviour and utilization of health facilities for schistosomiasis-related symptoms in Ghana. Plos Neglected Tropical Disease. 4(11): e867.doi.10.1371/Journal.pntd.0000867.

6. Dida, N., Darega, B., \& Abebe, A. (2015). Treatment seeking behaviour and associated factors among malaria suspected patients in Babezone, Southern Ethiopia: institutionbased cross-sectional study. Journal of Family medicine, 2(1),5.

7. Harold, J. (2016). College students' healthseeking behaviour plans in response imagined abdominal pain. A Thesis Submitted to the Graduate School, New Brunswick Rutgers, the State University of New Tersey.

8. Hjelm, K., \& Atwine, F. (2011). Health care seeking behaviour among persons with diabetes in Uganda; an interview study. BMC International Health and Human Rights, 11,1 .

9. Khajeh, A., Vardanjani, H. M, M. Salehi, A., Bhamani, N., \& Delavari, S. (2019). Health-seeking behaviour and its relating factors in South of Iran. Journal of Educational Health Promotion, 8, 183-187.

10. Nahejabin, F., Parveen, S. \& Begum, R. (2015). Disease Pattern and health seeking behaviour of slum dwellers in Dhaka City. International Journal of Medical and Health Research, 1(2), 4-8.

11. Mirandola, M., Gios, L., Davis, R. T., Furegato, M., Brevegheri, M., Folch, C., Stanekora, D., Nita, T., \& Stehlikora, D. (2017). Socio-demographic factors predicting HIV test seeking behaviour among MSS in GESU Cities. European Journal of Public Health, 27(1), 313-318.

12. Muhammed, S. (2016). Healthcare-seeking behaviour among the aged in Niger State, 
Nigeria. Unpublished masters Dissertation, Ahmadu Bellow University, Zaria.

13. Mohammed-Beiji, A., Arsanjang, S. Mohammed-Salehi, N. Anbari, Z., \& Ghaderi, E. (2015). Educated-related inequity in access and utilization of oral health care in Iran. Journal of Family Medicine and Primary Care, 4 (1), 35.

14. Moranker, T. L. \& Admassu, B. 92013). Determinants of help seeking and treatment seeking behaviour of tuberculosis patientsgender perspective: a systematic review. International journal of Evidence-based health Care, 11(3), 237.

15. Nnorom, C. (2019). Predisposing, reinforcing and enabling (PRE) factors: What they are and how to find them. Ernel Consulting.

16. Nwiko, K. M. (2021). Determinants of healthcare-seeking behaviour among women in Khana Local Government Area of Rivers State, Nigeria. Unpublished MSc Dissertation School of Graduate Studies, University of Port Harcourt, Nigeria.

17. Oberoi, S., Chaudhary, N., Patnaik, S. \& Singh, A. (2016). Understanding healthseeking behaviour. Jorunal of Family Medicine and Priamry Care, 5(2), 463-470.

18. Obiechina, G. O. (2014). An intervention programme for health care seeking behaviour of tuberculosis patients in Ibadan, South-West Nigeria. A Doctoral Thesis, School of Graduate Studies, University of Port Harcourt, Nigeria.

19. Olenja, J. M. (2003). Health seeking behaviour definition in context, university of Nairobi, East Africa Medical Journal, 8(2), 61-62.
20. Oslorberg, L. \& Blaschje, T. (2005). Adherence to medication. The New England Journal of Medicine, 353, 487-497.

21. Ren, X., Wu, Z., Mi, G., McGoogan, J. M., Rou, K., Shoa, Y. \& Zhang, N. 92017). HIV care0seeking behaviour after HIV Sdttesting among men who have sex with men in Beijing, China: global situation, issues and challenges. World Health Organization, Geneva.

22. Sauver, T. L. s, Warner, D. O., Yawn, B. P., Jacobson, D. J., McGree, M. E., Panratz, J. J., \& Roccia, W. A. 92013). Why patients visit their doctors: assessing the most prevalent conditions in a defined American population: In mayo Clinic Proceedings, 88(1) 56-57; Elsavier.

23. Thompson, A. E., Anisimowickz, Y., Miedema, B., Hogg, W., \& Lev, K. (2016). The influence of gender and other patient characteristics and health care seeking behaviour: a QUALICOPE study. Biomed Central Family practice. 17(1), 38-44.

24. Yimer, S., Holm-Hansen, C., Yimaldu, T., \& Bjune, G. (2009). Healthcare-seeking behaviour among pulmonary tuberculosis suspects and patients in rural Ethiopia: a Community-based study British Mountaineering Council of Public Health, 9, 454-459.

How to cite this article: Nwiko, Kuebeari M., Asogwa, Emmanuel U., Achalu, Ernest I.. Demographic determinants of health careseeking behaviour among women in khana local government area of Rivers State, Nigeria. International Journal of Research and Review. 2022; 9(1): 312-320. DOI: https://doi.org/10. 52403/ijrr.20220137 